patients' rights and their situation since 1 March 1993.

National Board of Medicolegal Affairs,

PB 265,

00531 Helsinki,

Finland

1 Sheldon T. Dutch law defines patients' rights. $B M 7$ 1994;308 617. (5 March.)

\section{Oral squamous cell carcinoma}

\section{Managed by specialists from different disciplines}

EDrToR,-Iain Hutchison states that "only six British medical schools offer any formal teaching in mouth examination by oral surgeons" and that "any patient with a red or white intraoral patch should attend their local oral surgery department as a matter of some urgency."

The investigation and management of cancer of the mouth and jaws is not the sole remit of oral surgeons but is an area in which there is an interface with many other specialties. As medica students in Glasgow, we were taught the examination of the oral cavity and the management of intraoral carcinoma by general surgeons; ear nose, and throat surgeons; plastic surgeons; and radiotherapists. In Newcastle Medical School, examination of the oral cavity and the managemen of oral malignancy is taught to the medical and dental students in lectures and on the wards by ear nose, and throat surgeons; plastic surgeons; and radiotherapists. Students are also encouraged, should they so desire, to attend one of the combined head and neck oncology clinics run by the above specialties.

It is now time the oral surgeons accept that there are many specialists from other disciplines who currently teach students and treat patients with malignant disease of the oral cavity.

NEIL R MCLEAN Consultant head and neck surgeon Department of Plastic and Reconstructive Surgery, Newcastle General Hospital, Newcastle upon Tyne NE4 6BE

1 Hutchison IL. Improving the poor prognosis of oral squamous cell carcinoma. $B M 7$ 1994;308:669-70. (12 March.)

\section{Results of screening are encouraging}

EDrToR,-Iain Hutchison highlights the need for action to improve the poor prognosis of ora squamous cell carcinoma. ${ }^{\prime}$ Until recently, there has been no organised screening programme for the detection of oral cancer and precancer in the United Kingdom and Europe despite the fact that screening programmes for cancer elsewhere in the body have led to appreciable reductions in mortality, and dentists themselves have shown a poor degree of diagnostic ability in their practices for early signs of disease.

In response to a rising incidence of oral carcinoma Marks and Spencer has implemented an oral precancer and cancer screening programme for its staff. All staff aged 40 years and over are invited to attend in their store for an annual examination of the oral mucosa. In addition, staff with one or more risk factors (smoking, excess alcohol intake, depleted haemoglobin levels, and positive family history) are specifically targeted.

During the implementation of the screening it became clear that there was widespread ignorance of oral carcinoma, which necessitated an education campaign to alert staff to the existence of this disease. Evaluation of the early results is encouraging. In an initial study involving staff at the head office an appreciable number of oral white and red lesions were detected. ${ }^{3}$ Evaluation of the full

programme continues and a review of the results will be published later.

Further initiatives through the Association of Industrial Dental Surgeons have been taken to encourage other companies to set up workplace screening programmes, preceded by education campaigns to raise awareness among employees and other health professionals. Urgent action is required to encourage the further development of screening programmes at the workplace and opportunistic screening in dental practices. This should be preceded by campaigns to raise awareness of oral cancer among health professionals and the public. Measures such as these will contribute to preventing one of the most devastating cancers that can affect the individual and family.

G P FEAVER Chief dental officer

Marks and Spencer plc

London W1A 1DN

1 Hutchison IL. Improving the poor prognosis of oral squamous cell carcinoma. $B M F$ 1994;308:669-70. (12 March.)

2 Nally FF. Oral medicine. Br Dent $\mathcal{f} 1988 ; 165: 145-6$.

3 Feaver GP. Screening for oral pre-cancer and cancer in a general dental practice. Dent Pract 1993;31(17):4-5.

\section{Survival in advanced breast cancer}

\section{Combination chemotherapy improves outlook}

EdToR,-I E Smith's editorial on palliative chemotherapy for advanced non-small cell lung cancer contains a worrying error of fact. ${ }^{1}$ The statement that an average improvement in survival of around three months after chemotherapy is more than has been shown for chemotherapy in advanced breast cancer is not correct.

It is true that relatively ineffective protocolsfor example, classic cyclophosphamide, methotrexate, and fluorouracil given over 14 days or mitozantrone, mitomycin $\mathrm{C}$, and methotrexate -often give disappointing results. However, effective combination chemotherapy given to patients with disseminated breast cancer produces an overall response rate of between $45 \%$ and $80 \%$, with a median duration of response of 5-13 months and a median duration of survival among responders of 15-33 months. This is an internationally recognised consensus opinion, so widely accepted that it has now been included in standard textbooks of cancer medicine. ${ }^{2}$ Contrary to widespread belief, such protocols can be given with far fewer side effects than in the past, and treatment is always stopped if there is no response, so that no patients receive chemotherapy that is not making them better.

L A PRICE UK representative,
New York Chemotherapy Foundation

London W1N 1DL

1 Smith IE. Palliative chemotherapy for advanced non-small cell lung cancer. $B M f$ 1994;308:429-30. (12 February.)

2 Harris JR, Morrow M, Bonadonna G. Cancer of the breast. In: De Vita VT Jr, Hellman S, Rosenberg SA, eds. Cancer: principles and practices of oncology. Philadelphia: J B Lippincott, 1993:1321.

\section{Author's reply}

EDITOR,-I do not dispute the data on response and survival quoted by L A Price, but these do not constitute evidence for an improvement in survival related to treatment. Data from randomised trials are required for this; to the best of my knowledge these do not exist for metastatic breast cancer (in contrast to non-small cell lung cancer), and certainly Price does not quote any.

IAN E SMITH

Royal Marsden Hospital, Consultant cancer physician Sutton, Surrey SM2 5PT

\section{Management of oesophageal cancer}

EDrToR,-With regard to future approaches to the management of oesophageal cancer, ${ }^{1}$ we suggest an initiative that could be immediately implemented and would improve survival-namely, consideration of the operator's experience. ${ }^{2}$ We have analysed data on admissions to hospital for oesophageal resection for carcinoma of the oesophagus or cardia in the West Midlands region in the three years April 1990 to April 1993 (table). As in Matthews $e t a l$ 's study, "frequent" operators were defined as those who performed six or more resections a year. Operative mortality was $8.9 \%$ for frequent operators and $16.9 \%$ for all other operators. There was no difference in the mean age of the patients between these two groups. In Matthews et als original series prognostic factors were similar in each group and lower operative mortality accounted for the improved five year survival of patients operated on by frequent operators. $^{2}$

Average number of oesophageal resections per year and number of operative deaths in West Midlands region, April 1990 to April 1993

\begin{tabular}{lccc}
\hline & $\begin{array}{c}\text { Patient } \\
\text { survived } \\
\text { and was } \\
\text { discharged }\end{array}$ & $\begin{array}{c}\text { Patient } \\
\text { died in } \\
\text { hospital }\end{array}$ & Total \\
Consultant's experience & 234 & 23 & 257 \\
Frequent operator & 211 & 43 & 254 \\
Other & 445 & 66 & 511 \\
\hline Total & & & \\
\hline
\end{tabular}

*Defined as one doing $\geqslant 6$ resections a year. $x^{2}=7 \cdot 23, P=0 \cdot 007$

The difference is due to the operators' experience rather than the experience of the unit in which they work (anaesthetic management, postoperative intensive care). When we restricted the analysis to hospitals with at least one frequent operator there was still a lower operative mortality among patients operated on by frequent operators $(23 / 257,8.9 \%)$ than among those operated on by all other operators $(10 / 57,17 \cdot 5 \%)$.

Operative skill presents a challenge both to purchasers of health care, who could move contracts to units with frequent operators, and to the professional audit process in these units. Both purchasing and audit have been introduced since Matthews et al's paper was published: can they effect a change that previous systems did not deliver?

North Birmingham Health Authority,

Birmingham B16 9SA

1 Ellis $P$, Cunningham D. Management of carcinomas of the upper gastrointestinal tract. $B M F$ 1994;308:834-8. (26 March.)

2 Matthews HR, Powell DJ, McConkey CC. Effect of surgical experience on the results of resection for oesophageal carcinoma. Br 7 Surg 1986;73:621-3.

\section{Non-heart beating organ donors}

\section{An important source of kidneys for transplantation}

EDrToR,-The results of the programme for obtaining organs from non-heart beating organ donors reported by $\mathrm{K}$ Varty and colleagues' are compatible with those from other centres worldwide $^{24}$ and show that such donors are an important potential source of kidneys for transplantation. We have been planning a similar programme but have hesitated because of uncertainty about the 
public response and the quality of the organs. Now that a national precedent has been set we intend to implement our programme.

Early cooling of the organs is crucial to success, but concern has been expressed over the legality of organ perfusion catheters being placed before consent has been obtained from the dead person's relatives. There is no case law on the subject, but the Human Tissues Act of 1961 could be interpreted as allowing this action. The person "lawfully in possession" of the body may give permission for organs to be removed provided he or she has "made such reasonable inquiry as may be practicable" and has no reason to believe that either the dead person or his or her relatives objected to organ donation. Thus it seems that the designated health service officer "in possession" of the body could give permission for organ perfusion. Public opinion is supportive, but the procedure might be construed as constituting interference with a corpse, which is a criminal act.

In planning our programme we have consulted with our coroner, local medicolegal experts, the health authority's legal department, and the regional ethics committee, and we intend to publicise the programme through the local media. This serves to inform people of our intentions, to canvass opinion, and to provide some protection if our actions are challenged legally.

We think it unfortunate that the paper by Varty and colleagues ${ }^{1}$ and that by $\mathrm{A} O \mathrm{O}$ Phillips and colleagues ${ }^{5}$ were published and commented on as a pair. The technique used by Phillips and colleagues did not entail in situ perfusion of the organs and is, in effect, the same as that abandoned when the criteria regarding brain stem death were established. This yields inferior and probably unacceptable results, and the paper serves to highlight this.

The planning, consultation, and education needed to initiate a programme to obtain organs from non-heart beating donors are considerable, and an experienced surgical team large enough to permit constant availability is essential. Such programmes could, however, herald the expansion in renal transplantation that has been urgently required for several years. Senior registrar in surgery R H MOORE Consultant nephrologist PJA GRIFFIN Associate specialist in transplantation R H H LORD Consultant transplant surgeon J R SALAMAN Cardiff Royal Infirmary, Cardiff CF2 1SZ

1 Varty K, Veitch PS, Morgan JDT, Kehinde EO, Donnelly PK, Bett PRF. Response to organ shortage: kidney retrieval programme using non-heart beating donors. BMF 1994;308:57 (26 February.)

2 Hattori R, Kinukawa T, Ohshima S, Matsuura O, Ono Y, Fujita T. Outcome of kidney transplantation from nonheart beating donors: comparison with heart beating donors. Transplant Proc 1992;24:1455-6.

3 Kootstra G, Wijnen R, van Hooff JP, van der Linden CJ. Twenty per cent more kidneys from a non-heart beating donor per cent more kidneys from a non-he

4 Castelao AM, Grino JM, Gonzalez C, Gilvernet S, Andres S, Séron $\mathrm{D}$, et al. Long term renal function of kidneys transplanted from non heart beating cadaver donors. Transplant Proc 1991;23:2584-6.

5 Phillips AO, Snowden SA, Hillis AN, Bewick M. Renal grafts from non-heart beating donors. BMf 1994;308:575-6. (26 February.)

\section{Old technique should be renewed}

EDITOR,-The increasing numbers of patients awaiting kidney transplantation in the British Isles has led to renewed interest in the use of non-heart beating organ donors. ${ }^{12} \mathrm{~A} \mathrm{~J}$ Wing and $\mathrm{R} \mathrm{W} \mathrm{S}$ Chang contend that the higher rate of primary non-function, greater mortality, and lower graft survival associated with non-heart beating donors lead to a number of clinical and ethical problems in their use. ${ }^{3}$ Our former experience in Belfast suggests that these problems may be less important than the recent studies suggest.

Twelve Belfast patients received renal transplants between 1965 and $1968 . .^{4}$ In 10 of these the initial warm ischaemia time (time elapsed from cessation of heart beat until perfusion of the organs with cold perfusion fluid) was recorded and ranged from 26-105 minutes (mean 82.6 minutes); in eight it was 74 minutes or longer. All kidneys functioned, after a period of early non-function. The shortest period of function was five weeks in a patient who died from a cerebral episode related to her original disease of tuberculosis, with a functioning graft Three of the grafts (initial warm ischaemia 89, 74, and 83 minutes) continue to function after 341 , 332 , and 329 months; one of these is recorded on Terasaki's 1994 listing as the longest surviving cadaver graft in the world (P I Terasaki, personal communication)

Between 1968 and April 1979, 160 cadaver grafts were carried out. In 53 the initial warm ischaemia time was 30 minutes or longer (range 30-80 (mean $47.5)$ minutes); five $(9 \cdot 4 \%)$ did not function. In 13 it was 60 minutes or longer (60-80 (65) minutes); all functioned. After this date only eight patients are recorded as having a warm ischaemia of 30 minutes or longer; seven of the kidneys functioned.

The use of non-heart beating donors in no way prejudiced patient or graft survival; on the contrary it contributed to some of our best results. Of these grafts, $91 \%$ functioned without the use of in situ perfusion. The change to heart-beating donors reduced the incidence and duration of postgraft oliguria, greatly reduced the logistical problems associated with retrievals outside the intensive care unit, and simplified the mechanisms of the surgica procedure, but it did not significantly change our results of renal transplantation.

With the increasing discrepancy between the number of potential recipients for kidney grafts and the number of kidneys available, we believe that we have an obligation to re-examine the use of non-heart beating donors. Our former experience suggests that this expertise could be renewed.

RICHARD A DONALDSON
Consultant urologist
JAMES F DOUGLAS
Consultant nephrologist
JOSEPH A KENNEDY
Consultant urologist
W GORDON LOUGHRIDGE
Consultant urologist
MARY G MCGEOWN
Consultant nephrologist

Department of Medicine,

Queen's University of Belfast,

Belfast City Hospital,

Belfast BT9 7AB

1 Varty K, Veith PS, Morgan JDT, Kehinde EO, Donnelly PK, Bell PRF. Response to organ shortage: kidney retrieval programme using non-heart beating donors. $B M{ }^{\prime}$ 1994;308: 575. (26 February.)

2 Phillips AO, Snowdon SA, Dean C, Hillis AN, Bewick M. Rena grafts from non-heart beating donors. BMF 1994;308:575-6. (26 February.)

3 Wing AJ, Chang RWS. Non-heart beating donors as a source of kidneys. BMF 1994;308:549-50. (26 February.)

McGeown MG. Pre-transplant management: an overview. In Short C, ed. Towards long term graft survival (in press).

\section{Vitamin K prophylaxis in infants}

EdrToR,-Editor's Choice in the edition of 2 April states incorrectly that the British Department of Health recommends that "doctors should give an oral dose of vitamin $\mathrm{K}$ at birth, a further dose a week later, and a third dose six weeks after birth to those babies who are breast fed." In fact, the Department of Health has stated that the available facts do not permit a clear consensus on the safest form of prophylaxis for newborn babies. Therefore it is important that paediatricians and midwives, and other health care professionals with responsibilities in this area of practice, should establish locally agreed policies for each maternity service for the administration of vitamin $\mathrm{K}$ to infants.

Advice similar to that quoted in Editor's Choice was given in the report of an independent group of experts convened by the British Paediatric Association with the support of the Department of Health. ${ }^{2}$ This report has been an important source of information for paediatricians and health professionals in other disciplines when they establish policies and practices locally. It emphasises the importance of ensuring that breast fed infants receive the vitamin $\mathrm{K}$ supplements they need.

I A F LISTER CHEESE Senior medical officer

Department of Health,

London SE1 8UG

1 Department of Health. Prophylaxis against vitamin $K$ deficiency bleeding in infants. London: DoH, 1992. (PLCMO(92)20, PLCNO(92)14.)

2 Vitamin $K$ prophylaxis in infancy. Report of an expert committee. London: British Paediatric Association, 1992.

\section{Ischaemic heart disease and cholesterol}

\section{Safety of cholesterol reduction remains in doubt}

EDITOR,-At their core the papers by M R Law and colleagues are about the advisability of reducing the cholesterol concentration in the general population, principally through restriction of dietary fat. ${ }^{1-3}$ This primary prevention mandate is plagued by controversies, while consensus exists for lowering cholesterol in patients with coronary heart disease. What, then, do the papers add to the issues surrounding population based dietary treatment to lower serum cholesterol concentrations?

With respect to evidence that a low cholesterol concentration is associated with increased mortality from causes other than coronary heart disease Law and colleagues emphasise that these relations are seen exclusively in community based populations rather than in (typically smaller) cohorts based on occupation. They assert that illness present at entry to community based studies caused a fall in cholesterol concentrations. The authors fail to recognise, however, that the largest "community based" cohort was in fact recruited primarily from employee groups. ${ }^{4}$ Moreover, no evidence is presented that more illness existed in community samples, that these conditions preceded a fall in cholesterol concentration in people healthy enough to volunteer for participation, and that such illnesses account for the associations with mortality. Quantitative attempts to remove the effects of conditions present at the time of baseline measurement of cholesterol (by exclusion of deaths occurring in the first five years of observation) have documented the persistence of numerous associations between low cholesterol concentration and mortality."

With respect to efficacy and safety, Law and colleagues combine the six major primary prevention trials ${ }^{6}$ with 19 secondary trials (typically using drug treatment) and a treatment study entailing resection of intestine. Aggressive treatment studies of patients known to have a serious illness cannot, however, be cited as supporting the efficacy and safety of a preventive intervention for the general public. Compared with previous metaanalyses, Law and colleagues add no new evidence concerning primary prevention through modification of diet; the only published trials entailed polyunsaturated fat substitution or supplementation rather than the currently recommended low fat diets. Secondary prevention trials of low fat 